\title{
SPECTRAL STUDY FOR THE EFFECT OF SOLVENT DIELECTRIC CONSTANT ON THE OPTICAL BAND GAP FOR (4-OXOTHIAZOLIDIN-2-YLIDENE) ACETONITRILE.
}

\author{
M. Ibrahim* and G. A. M. El Hag Ali** \\ Departments of Physics* and Chemistry**, Faculty of Science, Al Azhar University, Nasr city, Cairo1 1884, Egypt.
}

\begin{abstract}
:-
Heterocyclic compound of (4-oxothiazolidin-2-ylidene) acetonitrile was prepared in powder form. The crystalline nature of the prepared sample was checked by $X$ - ray diffraction $(X R D)$. IR absorption spectra were recorded on a Shimadzu 440 infrared spectrophotometer $\left(\mathrm{cm}^{-1}\right)$ using the $\mathrm{KBr}$ technique (Shimadzu, Japan). Reflection spectra of the powder sample were obtained in the wavelength range $(200-2500 \mathrm{~nm})$ at room temperature using spectrophotometer. Absorption and transmission spectra of the prepared sample were obtained in different solvents in the wavelength range (190-1100nm). The solvent used are acetone, dimethyformamid (D.M.F.) and glycerol. The measurements were carried out at room temperature using (JENWAY 6405 UVIVIS) spectrophotometer. The optical energy gap which is the difference between lowest unoccupied molecular orbital (LUMO) and highest occupied molecular orbital (HOMO) was estimated. The effect of the solvent dielectric constant on optical band gap was discussed. Keywords:- Optical band gap, FT-IR absorption and X-ray diffraction.
\end{abstract}

\section{1- INTRODUCTION}

Sulfur containing heterocyclic compounds finds enhanced interest for a long time because of their important medical applications [1]. Among this class of molecules (4-oxothiazolidin-2-ylidene) acetonitrile has been shown to have various important biological activities such as antimicrobial [2], antifungal [3], antiviral [4], antituberculostatic [5], anti-Hiv [6], cardio-protective [7], anticancer[8], anticonvulsant[9], antiinflammatory[10] and analgesic properties[11]. The chemical formula of the compound is shown in Fig.(1).

The aim of the present work are to investigate the optical behavior of (4-oxothiazolidin2-ylidene) acetonitrile system in crystalline and solution in three different solvents. The effect of dielectric constant of the solvents was considered by X-ray diffraction and IR absorption. The absorbance of the prepared system was also measured to study the effect of the solvent dielectric constant on the optical band gap. The solvent is used are acetone, dimethyformamid (D.M.F.) and glycerol.

\section{2- EXPERIMENTAL TECHNIQUES}

Yellow crystals, yield $72 \%$ (melting point around $180-82^{\circ} \mathrm{C}$ ), from ethanol was added to a solution of malononitile $(0.01 \mathrm{~mol})$ in acetic acid
$(20 \mathrm{~mL})(0.5 \mathrm{~mL})$ thioglycolic acid $(0.01 \mathrm{~mol})$. The reaction mixture was heated under reflux for $3 \mathrm{~h}$. The solid product formed was collected by filtration. IR absorption spectra was recorded in the frequency range $\left(400-4000 \mathrm{Cm}^{-1}\right)$. The optical reflection spectra of the obtained powder samples were accorded. The optical absorption of (4-Oxothiazolidin-2-ylidene) acetonitrile solved in acetone, dimethylformamid (D.M.F.) and glycerol were recorded in the wavelength range (190-1100 nm). The optical energy gap between HOMO and LUMO was determined and the effect of solvent on the optical band gap width was discussed.

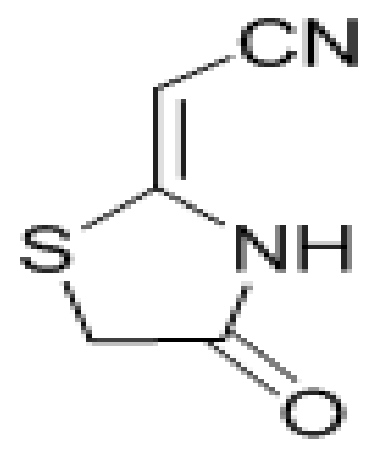

Fig. 1: The chemical formula of (4-oxothiazolidin-2-ylidene) acetonitrile. 
M. Ibrahim and G.A.M.El Hag Aly

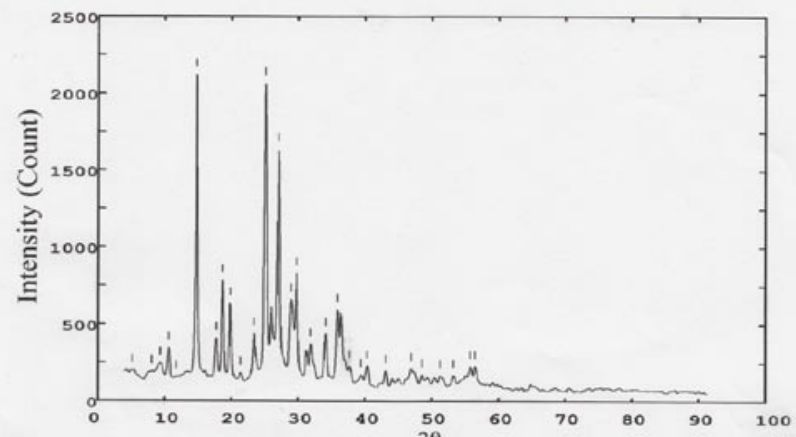

Fig. (2):- X-ray diffraction of (4-oxothizolidin-2-ylidene) acetonitrile.

\section{3- RESULTS AND DISCUSSION:-}

\section{3-1-:X-Ray Diffraction (XRD)}

The XRD pattern obtained for (4-oxothiazolidine-2-ylidene) acetonitrile at room temperature is given in Fig.(2). As shown, a,sharpe peaks centered at $2 \theta=14.7,25.05$ and $27.02 \theta$ are observed indicating the polycrystalline nature of the prepared sample.

\section{2- FT-IR STUDIED}

For getting information about the structural units, FT-IR absorption spectrum in the frequency range (400-4000 $\left.\mathrm{Cm}^{-1}\right)$ has been recorded for the (4-oxothiazolidin-2-ylidene) acetonitrile as shown in Fig.(3). The main absorption bands of the structural units are given in table (1).

Table (1):- IR absorption spectrum of (4-oxothiazolidin-2-ylidene) acetonitrile.

\begin{tabular}{|c|c|c|c|c|}
\hline Structural Unit & $\mathrm{NH}$ & $\begin{array}{c}\text { CH. } \\
\text { Aleph }\end{array}$ & $\mathrm{CN}$ & $\mathrm{CO}$ \\
\hline $\begin{array}{c}\text { Wave number } \\
\left(\mathrm{Cm}^{-1}\right)\end{array}$ & 3414 & 2945 & 2221 & 1722 \\
\hline
\end{tabular}

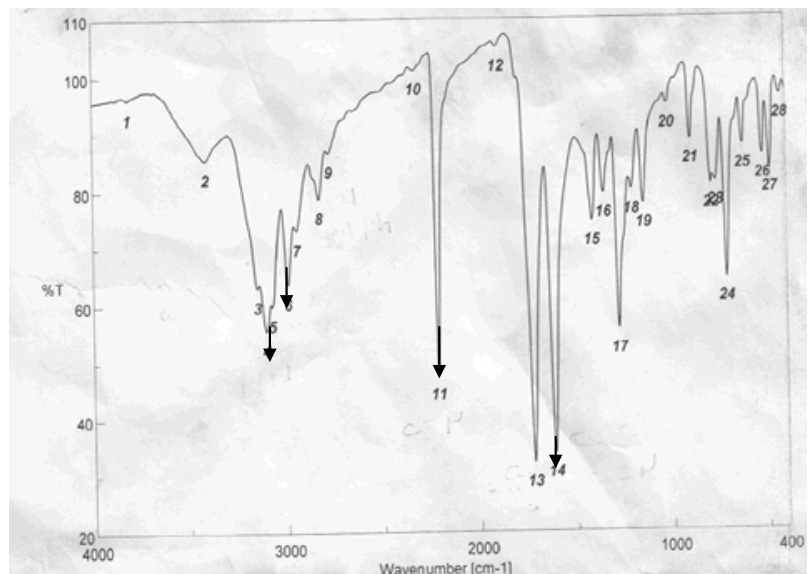

Fig. (3):- The FT-IR Spectrum data of (4oxothiazolidin-2-yliddene) acetonitrile
The spectrum reveals clearly the formation of $\mathrm{NH}, \mathrm{CH}, \mathrm{CN}$ and $\mathrm{CO}$ functional groups. This confirms that the prepared samples are (4-oxothiazolidin-2-ylidene) acetonitrile.

\section{3- Band gap}

Effect of Solvent Dielectric Constant on the Optical

\section{3-1:- Optical Band Gap Determination}

The transmission $T$ was measured in the wavelength range (190-1100 nm) using three different solvents acetone, D.M.F. and glycerol. Figs. (4 -a,b,c) show the transmission spectrum as a function of wavelength for three different solvents; the former two solvents are non polar i.e. of low dielectric constant. On contrary the third (glycerol) is a polar solvent because of high dielectric constant. The dielectric constants, the onset wavelength and the maximum values of transmission of the studied system for the three solvents are listed in table (2) [12].

Table (2):-dielectric constant, their onset wavelength and maximum values of $\mathrm{T}$ for (4oxothiazolidin-2-ylidene) acetonitrile.

\begin{tabular}{|c|c|c|c|}
\hline Solvent & $\begin{array}{c}\text { Dielectric } \\
\text { Constant } \\
\text { at } 25^{\circ} \mathrm{C}\end{array}$ & $\begin{array}{c}\text { Onset } \\
\text { Wavelength } \\
\text { at } 400 \mathrm{~nm}\end{array}$ & $\begin{array}{c}\text { Maximum } \\
\text { Values } \\
\text { of }(\mathrm{T})\end{array}$ \\
\hline Acetone & 20 & 390 & $70 \%(900 \mathrm{~nm})$ \\
\hline D.M.F. & 36.5 & 730 & $85 \%(1100 \mathrm{~nm})$ \\
\hline Glycerol & 47 & 740 & $65 \%(1070 \mathrm{~nm})$ \\
\hline
\end{tabular}

Many remarks can be extracted; first, the onset of the transmission depends on the type of solvent as given in table (2). Second, the degree of absorption depends on the solvent. Inspection of table (2) reveals that the onset wavelength increases by increasing dielectric constant of the solvent. Such results are expected. On the other hand, the degree of transmission $\mathrm{T}$ tends to increases with increasing wavelength. Table (2) gives the maximum values attended for each solvent and the corresponding wavelength.

The obtained data of transmission $T$ were used to calculate the absorption coefficient $\alpha$ through the well known relation:- $\alpha=-\frac{1}{t} \operatorname{Ln} T$, where $t$ is the thickness of the sample [13].

Figs. (5- a,b,c) show the relation between absorption coefficient $\alpha$ and wavelength $\lambda$ using 
Spectral study for the effect of solvent dielectric constant on the optical

the three different solvents. It can be seen that, all absorption coefficient spectrum follow a one commonpattern where $\alpha$ increases with increasing wavelength $\lambda$. In case of acetone $\alpha=1.29 \mathrm{~cm}^{-1}$ at wavelength $\lambda=380 \mathrm{~nm}$, then it increases up to $4 \mathrm{Cm}^{-1}$ at $\lambda=469 \mathrm{~nm}$ and finally it remains almost constant with increasing wavelength (in the high investigated wavelength range). In case of glycerol $\alpha=0.4 \mathrm{~cm}^{-1}$ at $\lambda=424 \mathrm{~nm}$ then, it increases with increasing wavelength. Finally, the variation of $\alpha$ with $\lambda$ of D.M.F. follow the same trend where $\alpha=0.1 \mathrm{~cm}^{-1}$ at $\lambda=660 \mathrm{~nm}$ and it increases with increasing wavelength. From the above results we can say that, the dielectric constant of the solvent plays an important role on the absorption coefficient value.

\section{3-4:- Reflection Spectrum}

The reflection spectrum $\mathrm{R}$ of the (4-oxothiazolidin-2-ylidene) acetonitrile powder sample was measured in the wavelength range (200$2500 \mathrm{~nm}$ ) using spectrophotometer at room temperature. Fig.(6) show the relation between absorbance A (where A=100- R) with wavelength $\lambda$. Extrapolating the curve gives the gap $\mathrm{E}_{\mathrm{g}}$, which lies between HOMO and LUMO width. The obtained value of $\mathrm{E}_{\mathrm{g}}$ was listed in table (3). The dependence of $A$ on wavelength $\lambda$ is shown in Figs. (7- a,b,c) solvent in acetone, D.M.F. and glycerol. The obtained values of $\mathrm{E}_{\mathrm{g}}$ are given in table (3). It can be seen that, the optical energy gap $\mathrm{E}_{\mathrm{g}}$ of the powder sample $(1.31 \mathrm{eV})$ is lower than that of the solutions. This can be accounted for by the fact that in the powder form the intermolecular interaction is smaller than that of the interaction between molecules [14]. For solution case the $\mathrm{E}_{\mathrm{g}}$ value has $1.59 \mathrm{eV}$ for D.M.F. For acetone and glycerol $\mathrm{E}_{\mathrm{g}}$ values increases This behavior can be attributed to the greater positive charge on carbon atom in case of acetone and glycerol with respect to that of dimethylformamide [15]. In the present case (molecular species) the absorption is due to the electron transition from HOMO to LUMO width. It is expected that dielectric constant of the solvent should change the position of both i.e. change the optical absorption. The higher value of $\mathrm{E}_{\mathrm{g}}$ is not expected due to the fact that acetone and glycerol exhibit less polarity with respect to D.M.F. This is most likely due to the internal hydrogen bonds in the glycerol molecule.

\section{4:- Conclusion}

Crystalline of (4-oxothiazolidin-2-ylidene) acetonitrile system was prepared. The crystalline nature of the prepared system was checked by Xray diffraction which revealed in polycrystalline form. IR absorption spectrum was recorded on a Shimadzu 440 infrared spectrophotometer using the $\mathrm{KBr}$ technique (Shimadzu, Japan). The spectrum reveals clearly the formation of $\mathrm{NH}, \mathrm{CH}$, $\mathrm{CN}$ and $\mathrm{CO}$ functional groups. The obtained data confirmed the formation of the (4-oxothiazolidin2-ylidene) acetonitrile. The optical energy gap

Table (3):- Effect of solvent on the optical gap Eg of (4-oxothiazolidin-2-ylidene). acetonitrile.

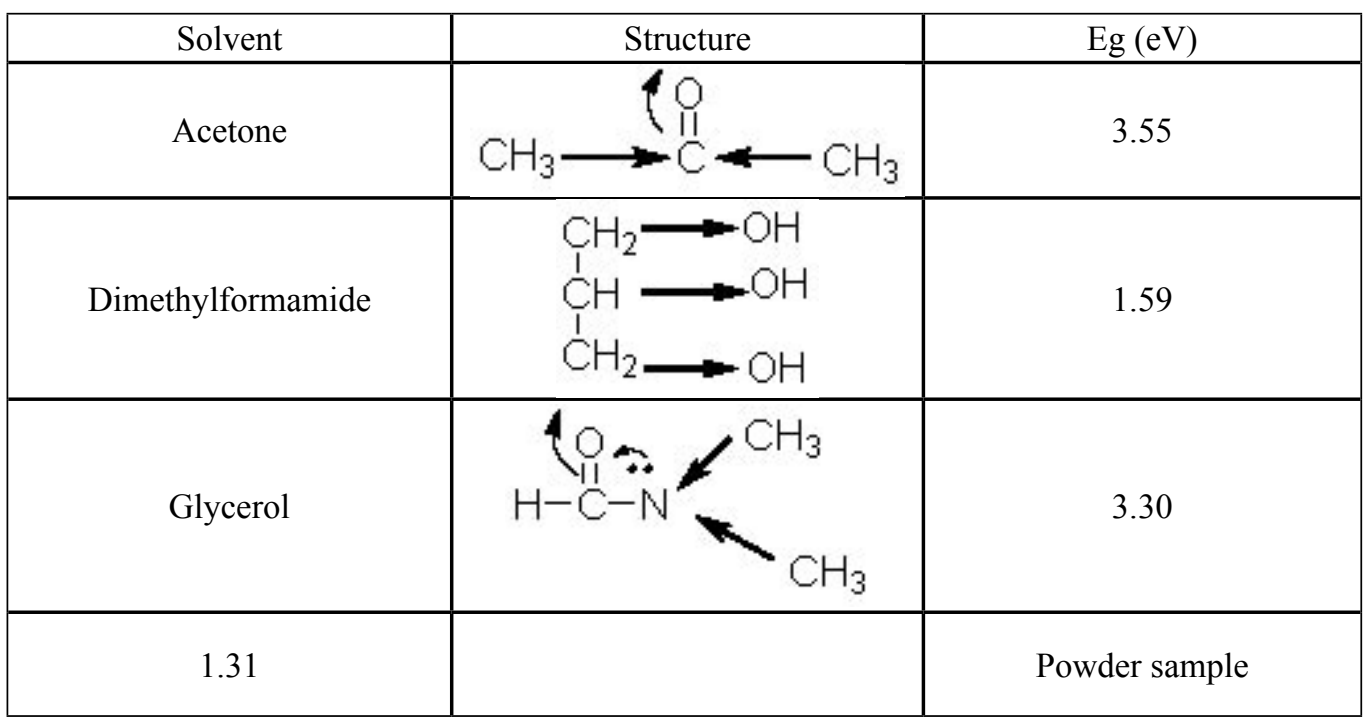


M. Ibrahim and G.A.M.El Hag Aly
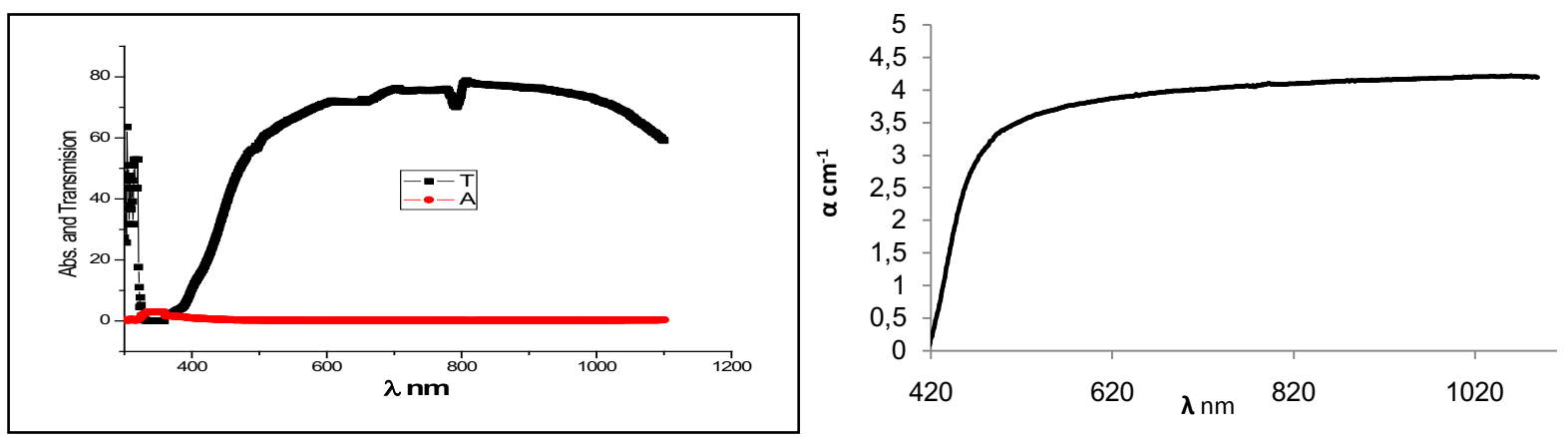

Fig(4-a):- The transmission $T$ and the absorbance $A$ as a function of wavelength $\lambda$ in acetone as a.

Fig(5-c):- The absorption coefficient $\alpha$ with wavelength $\lambda$ in glycerol as a solvent.

solvent

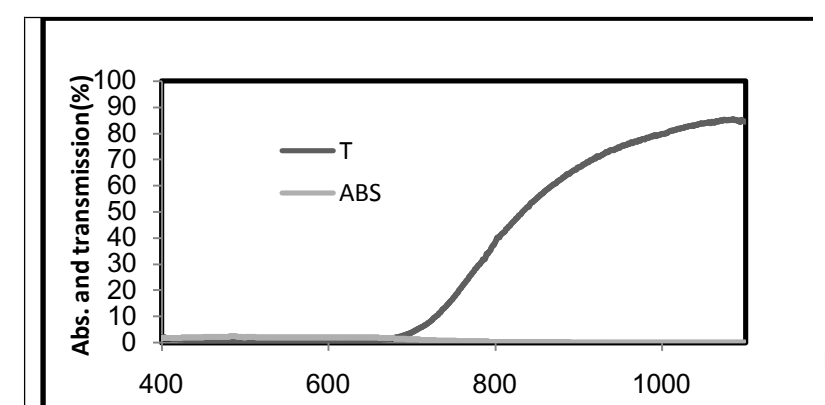

Fig(4-b):- The transmission T and absorbance $A$ as a function of wavelength $\lambda$ in D.M.F. as a solvent.

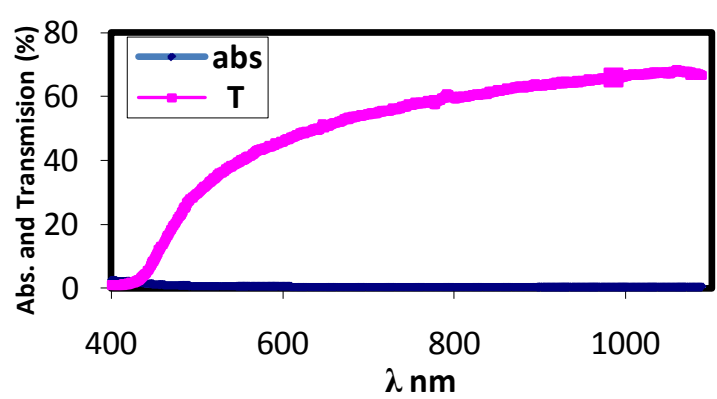

Fig(4-c) :- The transmission T and absorbance $A$ as a $f$ unction of wavelength $\lambda$ in glycerol as a solvent.

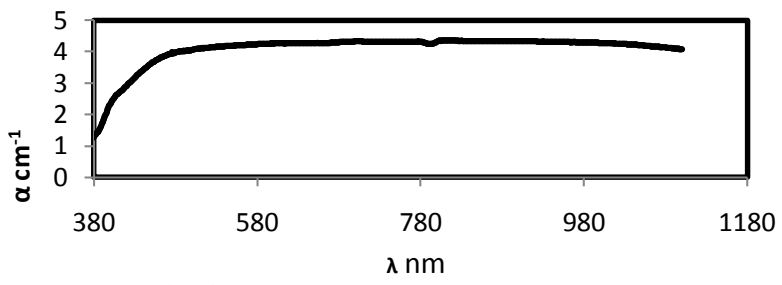

Fig(5-a):- The absorption coefficient $\alpha$ with wavelength $\lambda$ in acetone as a solvent.

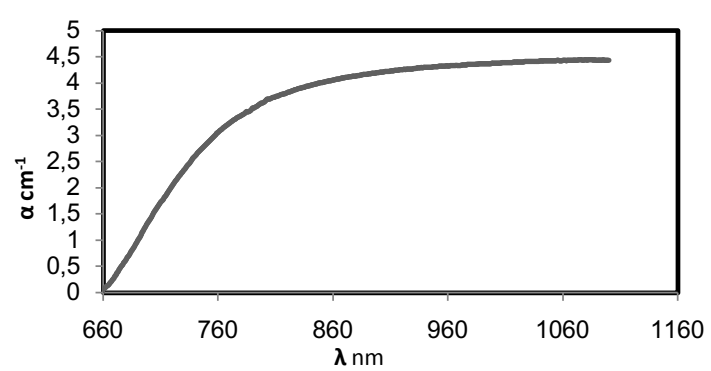

Fig (5-b):- The apsotption coefficient $\alpha$ with wavelength $\lambda$ in D.M.F. as a solvent.

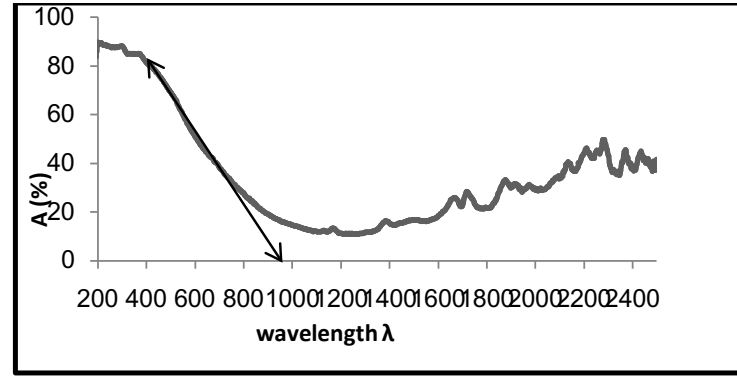

Fig. (6): - Relation between absorbance $A$ and wavelength $\lambda$ for powder sample.
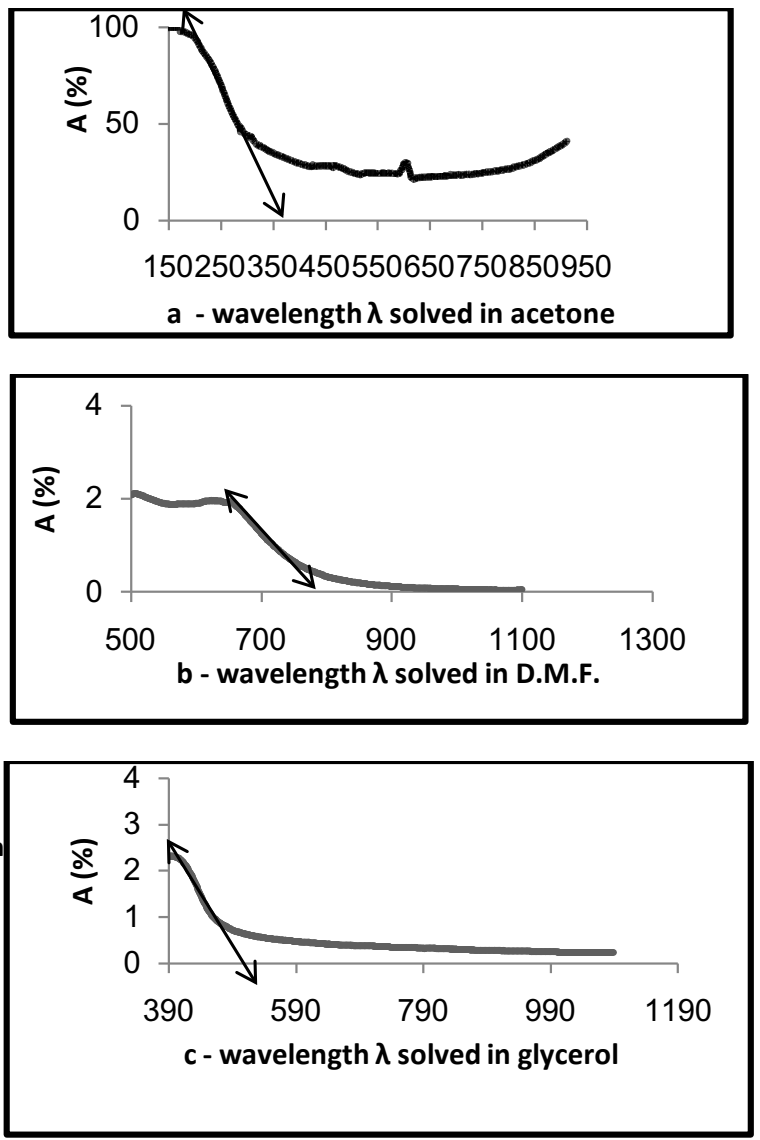

Fig. (7a,b.c): - Relation between absorbance $A$ and wavelength $\boldsymbol{\lambda}$ for(4-oxothiaxolidine-2-vlidene) acetonitrile. 
Spectral study for the effect of solvent dielectric constant on the optical

of the powder sample was determined and found to smaller than that of the solutions. The optical absorption of the prepared sample was studied in different three solvents. The solvents used are acetone, dimethylformamid (D.M.F.) and glycerol. It can be seen that, optical energy gap Eg has a value of $1.31 \mathrm{eV}$ in powder form. The value of $\mathrm{Eg}(1.59 \mathrm{eV})$ was obtained for D.M.F. However in cases of acetone and glycerol Eg values are higher. The effect of the solvent dielectric constant on optical band gap was discussed.

\section{REFERENCES:-}

1. Lalit, K. Shashi,B. and .KamalInt,J.J. Sci., 2012 ,2, 23.

2. Devappa, S.L. Reddy, K.R.V. Govinda, R. Reddy, K.B. Sahana, K.N. Smitha, N.C. Anand, Pradeep. Nitin, Kand Achuthanada... Int. J. Chem. Tech. Res., 2010, 2, 1220 .

3. Srinivas, A. Nagaraj, A. and Reddy, C.S. Eur. J. Med. Chem., 2010, 45, 235.

4. Ravichandran, V. Jain, A. Kumar, K.S. Rajak, H. and Agrawal, R.K. Chem Biol Drug Des., 2011, 78, 464.

5. Vintonyak, V.V. Warburg, K. Over, B. Hebar, K. Rauh, D. and Waldmann, H. Tetrahedron., 2011 , 67,6713.

6. Ravichandran, V. Prashantha, B.R.K. Sankar, S. and Agrawal, R.K. Eur. J. Med. Chem. , 2009, 44,1180.
7. Kato, T. Ozaki, T. and Ohi, N., Tetrahedron Asymmetry., (1999), 10, 3963.

8. Voss, M.E. Cartwer, P.H. Tebben, A.J. Scherle, P.A. Brown, G.D. Lorin, A. Xu, M. Lo, Y.C. Yang, G. Liu, R.Q. Strzem-ienski, P. Everlof, J.G. Trzaskos, J.M.and Decicco, C.P. Bioorg. Med. Chem. Lett., 2003,1b3, 533.

9. Agarwal, A. Lata, S. Saxena, K.K. Srivastava, V.K. and Kumar, A. Eur. J. Med. Chem.,2006,41, 1223.

10. Bhati, S.K. and Kumar, A. ().. Eur. J. Med. Chem., 2008, 43, 2323.

11. Sugumaran, M. Sethuvani, S. and Poornima, M..J. Pharm. Biomed. Sci., 2012,16,13

12. Ian M.Smallwood, Hand book of Organic Solvent,(1996).

13. G. Sharma, K.S. Thind, Manupriya, H.S. Kare, S.B. Narang, L .Gerward and V.K. Dangwal, Nuclear Instruments and Methods in Physics Research B 243 (2006) 345 .

14. M.H.Helal, S.A.El-Awdan, M.A.Salem, T.A. Abdelaziz, Y.A.Mohamed, A.A.El-Sherif, G.A.M. Mohamed, Spectrochimica Acta Part A; Molecular and Biomolecular Spectroscopy 135 (2015) 764

15. H.A.Goma, A.M.Nassar, G.A.M.El-Hag, A.H.AbdelMonsef, J. Pharm. Sci. Rev.23(2), Nov-Dec (2013) no. 66,411 